\title{
Outcomes of Type I Tympanoplasty using a Cartilage Shield Graft
}

\author{
Murad Ghazi Ahmed \\ MBChB, KBMS/Otolaryngology trainee \\ Sulaimani Teaching Hospital-Otolaryngology/Head and \\ Neck Surgery Center \\ Sulaimani, Iraq \\ +964(0)7705351313 \\ murad_ghazi@hotmail.com \\ Hiwa Asaad Abdulkareem \\ MBChB, FICMS (ENT), CABS (ORL-Head and Neck \\ surgery), Assistant Professor \\ Sulaimani Teaching Hospital/ ENT, Head and Neck \\ Surgery Center \\ Sulaimani, Iraq \\ hiwa ent@yahoo.com
}

\author{
Said M. Said Aljaff \\ MBChB, FICMS (ENT), FACS (ORL-Head and \\ Neck surgery), Professor \\ Rizgary Teaching Hospital/ENT Head and Neck \\ Surgery Center \\ Erbil, Iraq \\ said.mustafa@med.hmu.edu.krd
}

\begin{tabular}{l} 
Article Info \\
Volume 5-Special Issue: $4^{\text {th }}$ \\
International Conference on the Health \\
and Medical Science : Medical \\
Researches Improve Life Quality \\
(ICHMS 2020) \\
DOI: \\
10.24017/science.2020.ICHMS2020.11 \\
Article history: \\
Received: 22 September 2020 \\
Accepted: 28 September 2020 \\
\hline Keywords: \\
Air-bone gap, Bellucci classification, \\
Cartilage shield graft (CSG), Hearing loss \\
(dB), Tympanic membrane perforation, \\
Type I tympanoplasty surgery.
\end{tabular}

Article Info

Volume 5 - Special Issue: $4^{\text {th }}$

and Medical Science : Medica

Researches Improve Life Quality

(ICHMS 2020)

DOI:

Article history:

Received: 22 September 2020

Accepted: 28 September 2020

Keywords:

Cartilage shield graft (CSG), Hearing loss

(dB), Tympanic membrane
Type I tympanoplasty surgery.

\begin{abstract}
Background: Type I tympanoplasty surgery is an effective routine technic that had been used for tympanic reconstruction to improve hearing. Objectives: The aim was to measure the effect of type I tympanoplasty surgery using the cartilage shield graft (CSG) in term of graft uptake (anatomical outcome) and hearing gains (functional outcomes) of patients with poor prognostic factors. Method and Materials: In this study, 20 patients with perforation exceeded 50\%, but limited to the tympanic membrane were recruited for type I tympanoplasty surgery. The study was conducted in the Otolaryngology/Head and Neck surgery training center in Sulaimani Teaching Hospital in Sulaimani city for one year period. Bellucci classification was used to evaluate otorrhea risks. Results: The majority of patients were female $(90 \%)$, with a mean $\pm S D$ (standard deviation) of ages of $37.15 \pm 14.01$ years. Most of the patients $(40 \%)$ were presented with a mild hearing loss of 26-40 decibels (dB). Type I tympanoplasty surgery using the cartilage shield graft (CSG) had significantly decreased the hearing loss and air-bone gap (p-value $=0.046$ and 0.006 , respectively). The mean differences in hearing loss and air-bone gap were $5.05 \mathrm{~dB}$ and $6.75 \mathrm{~dB}$, respectively. Conclusions: CSG in type I tympanoplasty surgery is an effective solution in anatomical outcome (Graft uptake) and
\end{abstract}


Copyright $@ 2020$ Kurdistan Journal of Applied Research.

All rights reserved.

\section{INTRODUCTION}

Tympanic membrane perforation occurs in many ear diseases, such as chronic otitis media, and in every age [1-3]. Patients with tympanic membrane perforation are presented with different clinical symptoms such as hearing loss, otorrhea and wet ear; these perforations are the main cause of middle ear relapsing infections [4-5]. Usually hearing loss is proportional to the size of perforation and pneumatization of the middle ear and mastoid [6-7]. Type I tympanoplasty surgery is an effective routine technic that had been used for tympanic membrane reconstruction and clearing any residual ear diseases, this surgery is expected to lead to hearing gain [8-9]. Almost more than $85 \%$ of patients regain hearing after surgery [5]. After type I tympanoplasty surgery, other complains like otorrhea and wetness of ear can also be resolved [10].

Various forms of type I tympanoplasties, e.g., cartilage grafts and temporalis fascia grafts, had different outcomes in terms of hearing and success rates [11-12]. However, more studies that had been done recently are preferring cartilage graft in terms of success rate and hearing gain [3, 13-14]. Cartilage graft can significantly improve the outcomes in ear atelectasis and damaged tympanic membranes [3, 13-14]. Attempts had been performed to explore the relationship of hearing gain with different forms of tympanoplasty surgeries. A meta-analysis study performed by Tan et al. [13] reported that hearing gain could not be obtained in all forms of type I tympanoplasty surgeries; however, retaining $10 \%$ of decibels $(\mathrm{dB})$ of hearing loss have been considered as a good clinical outcome.

This study aimed to measure the effect of type I tympanoplasty surgery by using cartilage shield graft (CSG) on anatomical (graft uptake) and functional (hearing gain-pure tone audiometry) of patients with poor prognostic factors.

\section{PATIENTS AND METHODS}

This experimental study was conducted in the Otolaryngology/Head and Neck surgery training center in Sulaimani Teaching Hospital in Sulaimani city. Twenty patients from both sexes and different age groups who presented with tympanic membrane perforation that exceeded $50 \%$ of the total tympanic membrane surface area were selected for the study. Also, all patients had been briefed and signed a consent form for this study.

Pre-operatively, all patients were subjected to detailed history taking and clinical examinations. Besides, their hearing was evaluated subjectively and objectively; pure-tone average (PTA) hearing loss, PTA air-bone gap, and Bellucci classification were measured preand post-operatively for the patients. Also, follow up for all patients was done in the same training center.

The inclusion criteria was tympanic membrane perforations exceeding $50 \%$ but limited to the tympanic membrane. The exclusion criteria were the preoperative diagnosis of other than the inclusion criteria mentioned above beside patients who were followed up for less than three months, and any patient who refused to participate. Cartilage graft was harvested from the tragus (endaural approach) in the beginning of each surgery.

Data were analyzed statistically by using the IBM SPSS Statistics version 25. Test of 
normality has proceeded, and since data was not normally distributed, the non- parametric test was used for the inferential statistic. Wilcoxon signed-rank test has been used to know the differences in the mean of PTA-Hearing Loss and PTA-Air-Bone Gap in pre and postoperation. Also, a P-value of $\leq 0.05$ was considered a statistically significant association.

\section{RESULTS}

The mean \pm SD (standard deviation) of the age of the patients was $37.15 \pm 14.01$ years (ranged 11 to 72 years). Also, the majority of patients $(90 \%)$ were female (male: female ratio $=0.11: 1)$, from middle age group 26-47 years (65\%), and more than half of the patients $(55 \%)$ presented with left sided hearing loss (Table 1).

Table 1: Demographic features of the patients

\begin{tabular}{llll}
\hline Demographic features & Frequency & Percent \\
\hline Gender & Male & 2 & 10 \\
\cline { 2 - 4 } & Female & 18 & 90 \\
\hline Side & Right & 9 & 45 \\
\cline { 2 - 4 } & Left & 11 & 55 \\
\hline \multirow{2}{*}{ Age (year) } & $\leq 25$ & 4 & 20 \\
& & 6 & 30 \\
\cline { 2 - 4 } & $26-36$ & 7 & 35 \\
\cline { 2 - 4 } & $37-47$ & 1 & 10 \\
\cline { 2 - 4 } & $\mathbf{4 8 - 5 8}$ & 2 & 100 \\
\hline Total & & 20 & 5 \\
\hline
\end{tabular}

Most of the patients (40\%) suffered from a mild hearing loss $(26-40 \mathrm{~dB})$; however, moderate to moderately severe hearing loss (41-70 dB), and severe hearing loss (71-90 dB) affected only $30 \%$ and $10 \%$ of the patients, respectively. Percentage of patients with normal hearing $(0-25 \mathrm{~dB})$ had been increased post-operatively by $15 \%$ (Pre-operatively $20 \%$ vs. Postoperatively $35 \%)$. However, the percentage of patients with severe hearing loss $(71-90 \mathrm{~dB})$ remained unchanged post-operatively. In regard to ear dryness and according to Bellucci classification, all patients' condition had been shifted from occasionally wet ear (level 1) to dry ear (level 0) post-operatively (Table 2).

Table 2: The degree of hearing loss in pre and postoperative among the patients

\begin{tabular}{|c|c|c|c|}
\hline \multicolumn{2}{|c|}{$\begin{array}{l}\text { Level of hearing loss in pre- and post-operative } \\
\end{array}$} & Frequency & Percent \\
\hline \multirow{5}{*}{$\begin{array}{l}\text { Pre-operative degree of hearing } \\
\text { loss }\end{array}$} & Normal hearing $(0-25 \mathrm{~dB})$ & 4 & 20 \\
\hline & Mild hearing loss $(26-40 \mathrm{~dB})$ & 8 & 40 \\
\hline & Moderate hearing loss $(41-55 \mathrm{~dB})$ & 3 & 15 \\
\hline & $\begin{array}{l}\text { Moderate to severe hearing loss (56-70 } \\
\text { dB) }\end{array}$ & 3 & 15 \\
\hline & Severe hearing loss $(71-90 \mathrm{~dB})$ & 2 & 10 \\
\hline \multirow{5}{*}{$\begin{array}{l}\text { Post-operative degree of hearing } \\
\text { loss }\end{array}$} & Normal hearing $(0-25 \mathrm{~dB})$ & 7 & 35 \\
\hline & Mild hearing loss $(26-40 \mathrm{~dB})$ & 7 & 35 \\
\hline & Moderate hearing loss $(41-55 \mathrm{~dB})$ & 2 & 10 \\
\hline & $\begin{array}{l}\text { Moderate to severe hearing loss (56-70 } \\
\text { dB) }\end{array}$ & 2 & 10 \\
\hline & Severe hearing loss $(71-90 \mathrm{~dB})$ & 2 & 10 \\
\hline Pre-operative Bellucci classification & Level 1 & 20 & 100 \\
\hline $\begin{array}{l}\text { Post-operative Bellucci } \\
\text { classification }\end{array}$ & Level 0 & 20 & 100 \\
\hline Total & & 20 & 100 \\
\hline
\end{tabular}

Kurdistan Journal of Applied Research $\mid 4^{\text {th }}$ International Conference on the Health and Medical Science: Medical Researches Improve Life Quality (ICHMS 2020) | 102 
Furthermore, the means \pm SD of hearing loss, and air-bone gap had been significantly decreased after the surgery (p-values of 0.046 , and 0.006 , respectively), (Table 3 ).

Table 3: Hearing loss and air-bone gap in the pre and postoperatively

\begin{tabular}{llcccc}
\hline Variables & & N & Mean \pm SD & Range & $p$-values \\
\hline Hearing loss & Preoperative hearing loss & 20 & $43.05 \pm 21.93$ & $15-90$ & 0.046 \\
& & & & \\
& Postoperative hearing loss & 20 & $38.00 \pm 23.42$ & $5-90$ & \\
\hline Air-bone gap & Preoperative air-bone gap & 20 & $27.85 \pm 14.14$ & $10-50$ & 0.006 \\
& Postoperative air-bone gap & 20 & $21.10 \pm 12.01$ & $5-50$ & \\
& & & & \\
& & &
\end{tabular}

$\mathrm{N}=$ number; $\mathrm{SD}=$ standard deviation

\section{DISCUSSION}

In this study, the majority of patients were females (90\%), with a mean age of $37.15 \pm 14.01$. Nearly more than half of them (55\%) presented with left sided hearing loss, and these findings are controversial when we compared them with a similar study of T. Sajid et al. [9].

Most of the patients ( $40 \%)$ suffered from a mild hearing loss (26-40 dB); however, moderate to moderately severe hearing loss $(41-70 \mathrm{~dB})$ and severe hearing loss $(71-90 \mathrm{~dB})$ were $30 \%$, and $10 \%$, respectively. The percentage of Mild hearing loss (40\%) in this study was much less compared to the $75 \%$ of the mild hearing loss in the study of N. V. Deosthale et al. [10]. It had been shown that the perforation of the tympanic membrane is mostly associated with 20 dB of PTA [15].

In our study, cartilage graft in type I tympanoplasty surgery was effective in reducing patients' hearing loss. However, no clinical benefit was observed in hearing gains for the $10 \%$ of the patients who were presented with severe hearing loss. The study of B. Bhardwaj et al. [16] had also showed that $15 \%$ of their patients did not have any hearing gains after cartilage graft type I tympanoplasty surgery. Besides, the study of G. Batni et al. [17] showed results near to our findings; they found that $6 \%$ of their patients did not improve after type I tympanoplasty. Further, the success rate after type I tympanoplasty was ranged from $80-95 \%$ in the literature due to the severity of hearing loss pre-operatively [18-19]. The results of the current study showed about the same successful rate (i.e., 90\%). Therefore, it is wise to select the patients for tympanoplasty according to the severity of their hearing loss at presentation.

The percentage of patients with normal hearing $(0-25 \mathrm{~dB})$ pre-operatively had increased from $20 \%$ to $35 \%$ post-operatively. In comparison, the percentage of patients with severe hearing loss (71-90 dB) was remained unchanged pre- and post-operatively $(10 \%)$. The studies of $\mathrm{T}$. Sajid et al. [9] and N. V. Deosthale et al. [10] had also shown the similar outcomes in term of hearing gains; large perforation pre-operatively had poor post-operative clinical outcomes since hearing gains was noticed to be correlated directly to the size of the perforations.

Hearing loss and air-bone gap have significantly been reduced after the surgery ( $p$-value $\leq$ 0.04 ); the mean differences in hearing loss and air-bone gap were $5.05 \mathrm{~dB}$ and $6.75 \mathrm{~dB}$, respectively. The results of this study is comparable to other similar studies regarding cartilage graft in type I tympanoplasty [20-21]. However, the average hearing gain in this study was less by $10 \mathrm{~dB}$ compared to the study performed by B. Bhardwaj et al. [16] for cartilage graft in type I tympanoplasty surgery.

The current study also showed that CSG was successful in resolving patients' complain of wet ear; all the patients were presented with a certain level of ear wetness pre-operatively yet the operated ears in all the patients became dry post-operatively. Post-operative ear wetness can hurdle hearing gain after surgery. Nevertheless, this finding has remained statistically, unproven [10]. 


\section{CONCLUSION}

Cartilage shield graft (CSG) in type I tympanoplasty surgery is an effective solution for anatomical (Graft uptake) and functional (hearing gains) outcomes which had been reflected in reducing hearing loss and air-bone gap (average hearing gain of $5 \mathrm{~dB}$ ) in patients presented with tympanic membrane perforations. No improvement in the functional outcomes was observed pre-operatively in patients presented with severe hearing loss.

\section{CONFLICTS OF INTEREST}

The authors had nothing to declare

\section{REFERENCE}

[1] J. Dornhoffer, "Cartilage tympanoplasty: indications, techniques, and outcomes in a 1,000-patient series,” Laryngoscope, 113 (11), pp. 1844-1856, 2003.

[2] R. Mane, B. Patil, A. Mohite, V. V. Varute, "Bilateral type 1 tympanoplasty in chronic otitis media," Indian J Otolaryngol Head Neck Surg, 65 (4), pp. 293-297, 2013.

[3] D. Baklaci, I. Guler, I. Kuzucu, R. O. Kum, M. Ozcan, "Type 1 tympanoplasty in pediatric patients: a review of 102 cases," BMC Pediatr, 18 (1), pp. 345, 2018.

[4] S. Vaidya, J. K. Sharma, G. Singh, "Study of outcome of tympanoplasties in relation to size and site of tympanic membrane perforation," Indian J Otolaryngol Head Neck Surg, 66 (3), pp. 341-346, 2014.

[5] S. Gupta, P. Kalsotra, "Hearing gain in different types of tympanoplasties," Indian J. Otol, 19 (4), pp. 186-193, 2013

[6] H. Park, S. N. Hong, H. S. Kim, J. J. Han, J. Chung, M. W. Suh, et al., "Determinants of conductive hearing loss in tympanic membrane perforation," Clin Exp Otorhinolaryngol, 8 (2), pp. 92-96, 2015. Erratum in: Clin Exp Otorhinolaryngol, 8 (4), pp. 430, 2015, Seo, Myung-Whan [corrected to Suh, Myung-Whan].

[7] M. Aslıer, H. Özay, S. Gürkan, G. Kırkım, E. A. Güneri, "The Effect of Tympanic Membrane Perforation Site, Size and Middle Ear Volume on Hearing Loss," Turk Arch Otorhinolaryngol, 57 (2), pp. 86-90, 2019

[8] S. Shetty, "Pre-Operative and Post-Operative Assessment of Hearing following Tympanoplasty," Indian J Otolaryngol Head Neck Surg, 64 (4), pp. 377-381, 2012.

[9] T. Sajid, M. I. Shah, R. Ghani, M. Asif, "Type-I Tympanoplasty By Underlay Technique - Factors Affecting Outcome," J Ayub Med Coll Abbottabad, 29 (2), pp. 258-261, 2017.

[10] N. V. Deosthale, S. P. Khadakkar, P. D. Kumar, V. V. Harkare, P. Dhoke, K. Dhote, et al., "Effectiveness of Type I Tympanoplasty in Wet and Dry Ear in Safe Chronic Suppurative Otitis Media,” Indian J Otolaryngol Head Neck Surg, 70 (3), pp. 325-330, 2018.

[11] T. Yang, X. Wu, X. Peng, Y. Zhang, S. Xie, H. Sun, "Comparison of cartilage graft and fascia in type 1 tympanoplasty: systematic review and meta-analysis," Acta Otolaryngol, 136 (11), pp. 1085-1090, 2016.

[12] S. A. Lyons, T. Su, L. E. Vissers, J. P. Peters, A. L. Smit, W. Grolman, "Fascia compared to onepiece composite cartilage-perichondrium grafting for tympanoplasty," Laryngoscope, 126 (7), pp. $1662-1670,2016$.

[13] H. E. Tan, P. L. Santa Maria, R. H. Eikelboom, K. S. Anandacoomaraswamy, M. D. Atlas, "Type I Tympanoplasty Meta-Analysis: A Single Variable Analysis," Otol Neurotol, 37 (7), pp. 838-846, 2016.

[14] M. Salviz, O. Bayram, A. A. Bayram, H. H. Balikci, T. Chatzi, C. Paltura, et al., "Prognostic factors in type I tympanoplasty," Auris Nasus Larynx, 42 (1), pp. 20-23, 2015.

[15] P. Caye-Thomasen, T. R. Nielsen, M. Tos, "Bilateral myringoplasty in chronic otitis media," Laryngoscope, 117 (5), pp. 903-906, 2007.

[16] B. Bhardwaj, J. Singh, "Comparative Study of Hearing Improvement of Type 1 Tympanoplasty Using Temporalis Fascia and Conchal Cartilage as Graft Material," Indian J Otolaryngol Head Neck Surg, 71 (Suppl 2), pp. 1174-1178, 2019

[17] G. Batni, R. Goyal, "Hearing outcome after type I tympanoplasty: a retrospective study," Indian J Otolaryngol Head Neck Surg, 67 (1), pp. 39-42, 2015.

[18] N. Aslam, J. Iqbal, K. Mehmood, “Type I tympanoplasty underlay technique and results," Proc Shaikh Zayed Postgrad Med Inst, 15 (2), pp. 77-80, 2001.

[19] F. A. Fadl, "Outcome of type-1 tympanoplasty," Saudi Med J, 24 (1), pp. 58-61, 2003.

[20] J. L. Dornhoffer, "Hearing results with cartilage tympanoplasty," Laryngoscope, 107 (8), pp. 10941099, 1997.

[21] R. Hayati, T. Haryuna, D. Zahara, "Hearing threshold differences between pre and post tympanoplasty in patients with chronic suppurative otitis media," Bali Medical Journal, 7 (1), pp. 47 $50,2018$.

Kurdistan Journal of Applied Research $\mid 4^{\text {th }}$ International Conference on the Health and Medical Science: Medical Researches Improve Life Quality (ICHMS 2020) | 104 